\title{
Nipple Discharge Aspiration
}

National Cancer Institute

\section{Source}

National Cancer Institute. Nipple Discharge Aspiration. NCI Thesaurus. Code C38076.

An aspiration of nipple discharge using a fine needle to investigate the presence of disease. 